Abstracta Iranica Abstracta Iranica

Revue bibliographique pour le domaine irano-aryen

Volume 28 | 2007

Comptes rendus des publications de 2005

\title{
La Perse et la Grande Guerre. Téhéran, Institut Français de Recherche en Iran, 2002, 462 p. (Bibliothèque iranienne, 52)
}

\section{Asyeh Ghafourian}

\section{(2) OpenEdition}

Journals

Édition électronique

URL : http://journals.openedition.org/abstractairanica/18411

DOI : 10.4000/abstractairanica. 18411

ISSN : 1961-960X

Éditeur :

CNRS (UMR 7528 Mondes iraniens et indiens), Éditions de l'IFRI

\section{Édition imprimée}

Date de publication : 15 mai 2007

ISSN : 0240-8910

Référence électronique

Asyeh Ghafourian, « La Perse et la Grande Guerre. Téhéran, Institut Français de Recherche en Iran, 2002, 462 p. (Bibliothèque iranienne, 52) », Abstracta Iranica [En ligne], Volume 28 | 2007, document 213, mis en ligne le 18 septembre 2007, consulté le 10 décembre 2020. URL : http:// journals.openedition.org/abstractairanica/18411 ; DOI : https://doi.org/10.4000/abstractairanica. 18411

Ce document a été généré automatiquement le 10 décembre 2020.

Tous droits réservés 


\title{
La Perse et la Grande Guerre. Téhéran, Institut Français de Recherche en Iran, 2002, 462 p. (Bibliothèque iranienne, 52)
}

\author{
Asyeh Ghafourian
}

1 Les plus proches sont les plus mal servis... Cette publication de l'IFRI avait été oubliée.

2 Les communications faites lors du colloque organisé à Téhéran en mars 1997 sur la Première Guerre mondiale ont donné l'occasion à Oliver Bast, un des organisateurs du colloque, de les réunir en un recueil La Perse et la Grande Guerre. Bien que la Première Guerre mondiale ait suscité en Europe de nombreuses recherches, en Iran elle n'a attiré que marginalement l'attention des historiens. L'édition de ce livre est digne d'intérêt car elle réunit en son sein, différentes interventions qui démontrent à la fois les enjeux et les intrigues, mais aussi les rapports de force entre les belligérants dans cette région et les relations entre la Perse et ses voisins. La lecture de ce livre nous permet de changer d'angle de vue et de considérer cette période non seulement grâce aux archives nationales iraniennes mais aussi aux archives régionales, (utilisées notamment dans les articles de la troisième partie qui concerne les régions de l'Iran). Enfin l'ouvrage permet de comprendre les tenants et les aboutissants de l'intervention des troupes étrangères en Perse, et la réaction du pays.

Le livre contient quatre grandes parties. Première partie : L'intervention étrangère en Iran : Mohammad Hasan Kavusi-Erâqi : «Le problème de la neutralité persane » (pp. 27-44) ; Paul Luft : « British Policy in Estern Iran during World War I » (pp. 45-79); Saleh M. Aliev: "Significant Changes in Russia's Expansionist Policy towards Iran 1906-1917 » (pp. 81-91); Yann Richard: "Les relations franco-iraniennes après la Grande Guerre » (pp.93-110); Ali Rahmani : "L'Iran dans la stratégie allemande 1896-1921» (pp.111-122); Türkaya Ataöv: «Iran and Turkey: 1914-1918 » (pp. 123-139) ; Wolfdieter Bihl: «Persia's Role in the Foreign Policy of the AustroHungarian Empire during the First World War » (pp. 141-145). 
Deuxième partie : La réaction iranienne face à l'intervention étrangère : Seyyed Ali Modjani : «Le ministère des Affaires étrangères iranien 1914-1918» (pp.149-156) ; Nasrollâh Sâlehi : «Les fatwas des ulémas persans de Najaf et Kerbala » (pp. 157-176); Kâveh Bayât: «Novembre 1915 : le projet de transfert de la capitale » (pp. 177-192); Stéphanie Cronin: "The Government Gendarmerie and the Great War in Iran" (pp. 193-217) ; Sa'id Mir-Mohammad Sadeq : «Le comité des nationalistes et le journal Kâve, 1915-1917 » (pp. 219-235); Ali Mir-Ansari : «La Grande Guerre dans la poésie épique persane » (pp. 237-259).

5 Troisième partie : L'impact de la guerre sur les régions de l'Iran : Seyyed Qâsem Yâ-Hosseini : "La région de Buchehr: dispersion du pouvoir et rapports de forces " (pp. 263-276) ; Mohammad Bâqer Vosuqi : «L'Ayatollah Seyyed Abdolhossein Lâri et son 'manifeste pour la défense' (1915)» (pp. 277-291); Rahim Rais-Niâ: «Tabriz et l'intervention des armées étrangères 1915-1919» (pp. 293-316); Magdalena Golnazarian: "Les Arméniens de l'Azerbaïdjan iranien pendant la Première Guerre mondiale » (pp. 317-328) ; Florence Hellot-Bellier: «La première Guerre mondiale à l'ouest du lac d'Urmiye» (pp. 329-352); Michael Zirinsky: «American Presbyterian Missionaries at Urmia during the Great War » (pp. 353-372).

6 Quatrième partie : L'Iran et la question de la paix : Oliver Bast : « La mission persane à la Conférence de Paix en 1919: une nouvelle interprétation»(pp.375-425); Mansoureh Ettehadieh (Nezam-Mafi) : «Les illusions et les faits : l'Iran et la conférence de Versailles » (pp. 427-437).

7 Conclusion : Bert G. Fragner : «World War I as a Turning Point in Iranian History » (pp. 441-447).

Une traduction persane de l'ouvrage a été publiée à Téhéran en 1380/2001 par le Centre de Documentation et d'Histoire Diplomatique (Markaz-e asnād va tārīH-e dīplomāsī).

\section{INDEX}

Thèmes : 4.3. Histoire de l'Iran moderne (à partir de 1905)

\section{AUTEURS}

\section{ASYEH GHAFOURIAN}

Paris 